\author{
International Journal of Management Science and \\ Business Administration \\ Volume 4, Issue 1, November 2017, Pages 45-51 \\ DOI: $10.18775 /$ ijmsba.1849-5664-5419.2014.41.1006 \\ URL: http://dx.doi.org/10.18775/ijmsba.1849-5664-5419.2014.41.1006
}

\title{
The Influence of Person-Organization Fit and Person-Job Fit on Work Engagement among Policemen in Sumatera Utara
}

\author{
${ }^{1}$ Vivi Gusrini Rahmadani, ${ }^{2}$ Indah Rasulinta Sebayang \\ ${ }^{1,2}$ Faculty of Psychology, University of Sumatera Utara, Medan, Indonesia
}

\begin{abstract}
The aims of this study are to measure the influence of person-organization fit to work engagement, the influence of person-job fit to work engagement and the influence of both person-organization fit and person-job fit to work engagement. 411 policemen were involved as the participants of this cross-sectional study. The results show the suitability of individual characteristics with the characteristics of the organization (person-organization fit) and the demands of the job as policemen (person-job fit) affect the level of their work engagement. In addition to that, this study also shows the career stage and tenure of the policemen give impact toward the level of their work engagement. This study could serve as guidelines for policymakers in the implementation of human resource policies, for instance in the selection and training strategy and program.
\end{abstract}

Keywords: Person-organization fit, Person-job fit, Work engagement, Policemen.

\section{Introduction}

Work engagement is a positive affective-motivational and work-related psychological state characterized by vigor (high levels of energy and perseverance), dedication (a sense of significance, inspiration, and involvement) and absorption (being focused, fully concentrated and engrossed in one's work) (Schaufeli, Salanova, Gonzales-Roma, \& Bakker, 2002). Employees who are emotionally engaged will dedicate themselves to the organization and to fully participate in their work with great enthusiasm (Markos \& Sridevi, 2010). Engaged workers outperform satisfied employees (Rich, Lepine, \& Crawford, 2010), are intrinsically motivated and work hard because they love to do so and not because they have to do so (Schaufeli, 2012). Moreover, they display innovative behaviors at work (Chang, Hsu, Liou, Tsai, 2013). By incorporating and managing engaged workers, organizations will increase their performance not only at the individual and team level but also at the organization and business unit level (Torrente, Salanova, Llorens, \& Schaufeli, 2012; Schaufeli, 2012; Salanova, Llorens, Cifre, Martínez, 2014). In sum, work engagement results are critically important for organizations' competitive advantage, such as high labor productivity, job satisfaction, lower turnover rates, customer satisfaction, loyalty, and profitability criteria.

Nevertheless a number of studies have shown that the level of employee engagement is still relatively low, as in the US study found that only $17 \%$ of employees are engaged and globally study obtained only $31 \%$ of employees are engaged, especially in the South East Asian region as much as 26\% of employees are engaged (Perrin, 2003; Kular, Gatenby, Rees, Soane, \& Truss, 2008; Blessing White, 2011). In addition to that, there is still a lack of research about the level of work engagement in public sector, especially in Indonesia. This research using the policemen in Sumatera Utara as the participants since the policeman is one of the most important jobs in the country with important roles and tasks as well. As gatekeepers to the criminal justice system, the police force must have a high professionalism to safeguard the public, improve law enforcement, especially regarding extraordinary crimes such as terrorism, drugs, and corruption as well as to increase synergy with other law enforcement agencies. However, critics have been addressed to the police force of Indonesia, for instance, as the organization with a high level of corruption and incompetent workers (Davis, Meliala, \& Buttle, 2013). This study tries to measure the level of work engagement among policemen in Sumatera Utara and find predictors to increase the level of their work engagement. 
One of the most important factors to ensure that human resources can support organizational performance is the consideration of the match between the value of the individual with the organization (person-organization fit) and also consider the match between the value of the individual to the job (person-job fit). The organization's ability to recruit and retain a number of qualified employees are a major source of competitive advantage (Rynes \& Barber, 1990). Personorganization fit and person-job fit explores how individuals interact with their environment in an effort to understand the factors that affect the quality of work (Chatman, 1989; Kristof-Brown, Zimmerman, \& Johnson, 2005). In this study, we used person-organization fit and person-job fit as the predictors. These constructs are widely used in the employees' selection context. Furthermore, the overall objectives of this study are to measure the influence of person-organization fit to work engagement, the influence of person-job fit to work engagement and the influence of both person-organization fit and person-job fit to work engagement.

\subsection{Work Engagement}

Kahn (1990) revealed that the members of an organization will be tied up with their work and then they will work and express themselves physically, cognitively and emotionally through their performance. The definition of work engagement by Schaufeli, Salanova, Gonzalez-Roma \& Bakker (2002) is the most used definition research studies. They define work engagement as a positive affective-motivational and work-related psychological state characterized by vigor, dedication, and absorption. Work engagement is positively associated with a form of employees' physical expression, cognitive, and emotional about their work and organization. Based on this definition, Schaufeli \& Bakker (2003) conceptualized aspects of engagement, as follows:

\subsubsection{Vigor}

Vigor is the outpouring of energy and mental strength during the work, the courage to exert every effort in completing a job, and perseverance in difficulties. It also means the spirit to devote efforts to one's work, an attempt to continue energetic at work, and a tendency to keep trying in the face of adversity or failure of the task.

\subsubsection{Dedication}

Dedication is a strong feeling towards the job, a sense of significance, enthusiasm, pride, inspiration, and challenge.

\subsubsection{Absorption}

Absorption is marked with full concentration, a deep interest in work where time was passed fastly. An individual who scores high on absorption usually feels interested in his work, immersed in his work, and it is difficult to break away from his job. There are several factors that affect the work engagement which related to the organization, job characteristic, and working conditions, namely person-organization fit and person-job fit.

\subsection{Person-Organization Fit}

Person-organization fit is one of the concepts of a broader concept that person-environment fit (Darnold, 2008). Personorganization fit is a concept that is intended to discuss the fit between the individual and the organization where he worked. It is also associated with the job selection, job satisfaction, organizational commitment, turnover and psychological well-being (Darnold, 2008). Person-organization fit is broadly defined as the fit between the organization's values with individual values (Kristof, 1996; Netemeyer et al., 1999). In research on employee selection, organization fit person can be defined as a match or fit between prospective employees with the attributes of the organization (Judge \& Ferris, 1992). Person-organization fit based on the assumption the individual's desire to maintain their compliance with the organization's values (Schneider, Goldstein, \& Smith, 1995). Person-organization fit has been defined and conceptualized into four dimensions (Kristof, 1996; Sekiguchi, 2004), namely:

\subsubsection{Value Congruence}

It is a fit between the intrinsic value of the individual with an organization that makes people feel comfort and confidence being at work. A sense of calm and comfort in work stimulates employees' ability, thereby increasing their performance.

\subsubsection{Goal Congruence}

It is a fit between individual objectives with the organization including the leaders and co-workers. The purpose of the employees joined the organization not just merely looking for income, but they also have other missions to be achieved. 
If employees have a common mission with the leaders and another employee, the employee will also feel comfortable at work.

\subsubsection{Needs of Employee Fulfillment}

It is a fit between the needs of employees with the working environment such as work systems and organizational structures. These needs may include the salary and working facilities. If employees' needs can be met by the company, they will feel cared for and eventually they can improve their spirits.

\subsubsection{Culture Personality Congruence}

It is a fit between the personality of each individual and organizational climate or culture. Several previous studies indicate that when individuals and organizations have the same value, then it will improve the performance of individuals (Silverthone, 2003).

\subsection{Person-Job Fit}

Person-job fit is a fit between the characteristics of the tasks and the individual's ability to perform these tasks. The fit between the employees' ability and the job demands will increase employees' commitment to the job (Meyer \& Allen, 1997).Sekiguchi (2004) defines the concept of person-job fit in the traditional basis for the selection of employees. Kristof-Brown, Zimmerman, \& Johnson (2005) describes the person-job fit as the fit between individuals with jobs or tasks performed in the workplace. Similarly, Edwards (1991) defines person job fit as fitting the ability of the individual to the demands of a job. Some dimensions of person-job fit according to Robbins (2006), namely:

\subsubsection{Ability}

The ability can be defined as an individual's capacity to perform various tasks in a job. In other words, the ability is a function of knowledge and skills.

\subsubsection{Attitude}

The attitude is an evaluative statement that favorable or unfavorable about the object, person, or event.In organizations, an attitude can influence workplace behavior, for instance, if a worker feels sure that he earned a reward because of his work performance, but he did not get that, then naturally he will form such an attitude that, in turn, will affect his behavior at work.

\subsubsection{Interest}

Interest is the attitude that makes people happy of an object, a situation or certain ideas. This was followed by feelings of pleasure and a tendency to seek objects that endeared it. Employees' interest is one of determining factors whether they will fit with for certain jobs or not.

Bohlander \& Snell (2004) suggested that the person-job fit is an effort to help identify which kind of employees are needed in certain jobs to achieve success, including the knowledge, skills, and other factors that may refer to the acquisition of superior performance, therefore it is very important variables considered by the company. Employees who do not have job suitability are predicted difficult to demonstrate professionalism because they do not feel in accordance with the jobs, resulting in the reluctance to enhance their capabilities. On the other hand, employees who feel accordance with the job type, they improve their abilities and skills so that they can work optimally.

\subsection{The Influence of Person-Organization Fit and Person-Job Fit to Work Engagement}

There are many factors that contribute to work engagement, one of which is the person-organization fit (Kristof, 1996). Studies of the person-organization fit has a deep understanding of improving the compatibility between employees and the company, retaining employees in the long term to improve customer satisfaction and employee commitment to the company, as well as improving individual outcomes in organizations (Kristof, 1996; Chatman, 1991; O'Reilly et al., 1991). When the values of individuals and organizations are alike, it will increase job satisfaction and performance and will reduce employee stress (Silverthone, 2003). Furthermore, job satisfaction is a factor that affects the work engagement (Robbins, 2006). In addition to that, Scheineder (1988) argued that individuals feel comfortable in the organization which fits with their own characteristics. Results from several studies indicate that the perceived similarity of employees' values 
with the organizational is positively associated with affective outcomes such as satisfaction, commitment, and engagement (Cable \& Judge, 1996). Kristof-Brown, Zimmerman \& Johnson (2005) suggested that the person-job positively influence the attitudes and work behavior. Moreover, it also increases employees' commitment and achievement motivation (Behling, 1998). According to Edwards (1991), person-job fit positively increase job satisfaction, motivation, performance, attendance, and retention. If there is a match between what employees' want and what they receive from performing a job, it will increase their job satisfaction, adjustment, and organizational commitment.

According to Scroggins (2008), person-job fit found to be a significant predictor of meaningful work. In a similar way, meaningful work can be found in the workplace by ensuring alignment between an individual's competencies, values, and purpose and the job (Chalofsky, 2003). May, Gilson \& Harter (2004) found that meaningfulness, security, and availability has a significant relationship with the engagement. They also found that job enrichment and precision tasks (role fit) is a positive predictor for meaningfulness. This shows that employees who feel comfortable with the job can increase the level of work engagement through positive work meaningfulness.

\section{Research Methodology}

Participants in this research were 411 policemen in Sumatera Utara. We used 3 measurement scales, and collected data were examined by using multiple regression analysis. Work engagement is measured by Utrecht Work Engagement Scale (UWES) from Schaufeli et. al (2002). Person-organization fit is measured by a P-O fit scale which is based on the theory from Kristof (1996). Person-job fit is measured by a P-J fit scale which is based on the theory from Robbins (2006). The demography data showed there were 391 male participants $(95.13 \%)$, and 20 females $(4.87 \%)$. The age ranges were 15 24 years in a number of 59 people (14:36\%), 25-44 years in a number of 195 (47.44\%), 45-64 years in a number of 157 people $(38.20 \%)$.

\section{Results and Discussion}

Correlation and multiple regression analyses were conducted to examine the relationship between work engagement and the predictors. Table 1 and 2 show the coefficient correlations for the key variables of this study. There is a positive significant correlation between P-O fit and work engagement $(r=0.456, p<0.01)$, between P-J fit and work engagement $(\mathrm{r}=0.442, \mathrm{p}<0.01)$.

Table 1: The Influence of P-O fit to Work Engagement

\begin{tabular}{|c|c|c|c|c|}
\hline Model & R & R Square & Adjusted R Square & $\begin{array}{c}\text { Std. Error of the } \\
\text { Estimate }\end{array}$ \\
\hline 1 & .456 & .208 & .206 & 7.09881 \\
\hline
\end{tabular}

Table 2: The Influence of P-J fit to Work Engagement

\begin{tabular}{|c|c|c|c|c|}
\hline Model & R & R Square & Adjusted R Square & $\begin{array}{c}\text { Std. Error of the } \\
\text { Estimate }\end{array}$ \\
\hline 1 & .442 & .195 & .193 & 7.15661 \\
\hline
\end{tabular}

For testing the influence of P-J fit and P-O fit on work engagement we have performed regression analysis.

Table 3: The Influence of P-O fit and P-J fit to Work Engagement

Model Summary

\begin{tabular}{|c|c|c|c|c|}
\hline Model & R & R Square & Adjust R Square & Std. Error of Estimate \\
\hline 1 & .496 & .246 & .242 & 6.93674 \\
\hline
\end{tabular}

a. Predictors: (Constant), person job fit, person organization fit 


\begin{tabular}{|c|c|c|c|c|c|c|}
\hline \multicolumn{1}{|c|}{ Model } & Sum of Squares & Df & Mean Square & F & Sig \\
\hline \multirow{2}{*}{1} & Regression Residual & 6396.179 & 2 & 3198.090 & 66.463 & .000 \\
& Total & 19632.273 & 408 & 48.118 & & \\
& & 26028.453 & 410 & & & \\
\hline
\end{tabular}

a. Predictors: (Constant), person job fit, person organization fit

b. Dependent variable: work engagement

As can be seen in Table 3, each of the predictors is positively and significantly correlated with the criterion, indicating that those with higher scores on these variables tend to have higher work engagement. The multiple regression model with two predictors produced $\mathrm{R}^{2}=0.246, \mathrm{~F}(2,408)=66.463, \mathrm{p}<.001$. It indicates that $24.6 \%$ of the variance in work engagement has been significantly explained by the two variables, namely person-organizational fit and person-job fit This study attempts to examine the influence of person-organization fit and person-job fit with work engagement among policemen in Sumatera Utara. The result of this study is in accordance with previous studies, in which there is positive P-O fit and P-J fit to work engagement, such as Hamid \& Yahya (2011). According to Hamid \& Yahya (2011), employees' who fit with job demands may know better their job implementation by applying their knowledge, skills, and abilities and consequently helps them engage in their work. In addition to that, employees' who fit organizational characteristics will own and able to fulfill the vision and mission of the organization, consequently helps them engage in their work. Furthermore, the influence of person-job fit and work engagement was supported by previous research (Scroggins, 2008). Employees' who are highly fit with their job tend to exert their best effort and find their job meaningful that consequently make them more engaging towards their job.

Based on the data categorization, $90.8 \%$ of the participants have a medium level of work engagement. Furthermore, $47.44 \%$ and $38.20 \%$ of all participant are at the establishment (25-44y) and maintenance (45-64) career stage respectively (Super, 2012). At this stage, employees secure their position and make some adjustment to improve their position. They want to stabilize their chosen career which could also impact their P-O fit and P-J fit. Lastly, 69.83\% participants have more than 10 years long tenure. Morrow and McElroy (1987) found the relationship between commitment and tenure as U- shaped, with higher levels of commitment reported by employees with 2 or fewer years, or greater than 10 years of experience. Thus, the organizational commitment is one of the impacts of work engagement (Bakker, Demerouti \&Verbeke, 2004).

\section{Conclusion}

$\mathrm{P}-\mathrm{O}$ fit was positively related to policemen' work engagement which is consistent with previous research. The more congruence between policemen' characteristics and their institutions' characteristics (P-O fit), the higher the level of their work engagement. This is applied in Person-Job fit and work engagement relationship as well.

The closer the congruence between policemen's attributes and the job demands (P-J fit), the higher the level of their work engagement. The study reveals the influence of person-organization fit (P-O fit) and person-job fit (P-J fit) towards work engagement among policemen in Sumatera Utara. It proves that both person-organization fit and person-job fit altogether is crucial to increase the level of work engagement.

The regression model can be used to predict the level of work engagement among policemen in Sumatera Utara. The regression equation of this model is:

Work Engagement $=8.713+(0.807$ P-O fit $)+(0.414$ P-J fit $)(1)$

This study also shows the level of work engagement of the participants, namely policemen mostly in medium level $(98.8 \%)$. 


\section{Suggestion}

This study could serve as guidelines for policymakers in POLRI institution in the implementation of human resource policies, for instance, in the selection and training strategy and program. In order to maintain and increase the level of work engagement of the policemen, the selection process is crucial not only to emphasize the ability of the candidates but also the congruence of their values and the values of the POLRI institution. It is recommended do organization to conduct the detailed continuous survey of person-organization fit and person-job fit to maintain the level of work engagement.

\section{References}

- Bakker, A. B., Demerouti, E., \& Verbeke, W. (2004). Using the job demands-resources model to predict burnout and performance. Human Resource Management, 43, 83-104. Crossref

- Behling, O. 1998. Employee selection: Will intelligence and conscientiousness do the job? Academy of Management Executive 12 (1): 77-86.

- Blessing White. (2006). Employee Engagement Report 2006 Blessing White, Inc. Princeton, New Jersey.

- Bohlander, G. \& Snell, S. (2004). Managing human resources, 13th Edition. Thomson/South-Western. Mason, OH.

- Cable, D. M, and Judge, T. A. (1996). Person-organization fit, job choice decisions, and Organizational entry. Article. Organizational Behavior and Human Decision Processes. 67(3), 294-311. Crossref

- Chalofsky, N. (2003). An emerging construct for meaningful work. Human Resource Development International, 6, 69-83. Crossref

- Chang, H.T., Hsu, H.M., Liou, J.W., Tsai, C.T. (2013) Psychological contracts and innovative behavior: a moderated path analysis of work engagement and job resources. Journal of Applied Psychology, 43, 2120-2135. Crossref

- Chatman, J.A. (1991). Matching people and organizations: Selection and socialization in public accounting firms. Administrative Science Quarterly, 36, 459-484. Crossref

- Darnold, T. (2008). Perceived person-organization fit: Moving beyond correspondence- based explanations. Theses and Dissertations. Iowa Research Online. University of Iowa

- Davies, S. G., Meliala, A., \& Buttle, J. (2013), Indonesia's secret police weapon (Jan-Mar 2013 ed.), Inside Indonesia, retrieved 8 December 2015

- Edwards, J. R., 1991. Person-job fit: A conceptual integration, literature review, and methodological critique. International Review of Industrial and Organizational Psychology. 4, 279-291.

- Hamid, S., \& Yahya, K. (2011). The relationship between person-job fit and person- organization fit on employee's work engagement: A study among engineers in semiconductor companies in Malaysia. Annual Conference on Innovations in Business \& Management. London, UK.

- Judge, T. A., \& Ferris, G. R. (1992). The elusive criterion of fit in human resources staffing decisions Human Resources Planning, 15(4), 47-67.

- Kahn, W.A. (1990). Psychological conditions of personal engagement and disengagement at work. Academy of Management Journal. 33(4),692-724. Crossref

- Kristof, A.L. (1996). Person-organization fit: An integrative review of its conceptualizations, measurement, and implications. Personnel Psychology, 49(1),1-49. Crossref

- Kristof-Brown, A.L., Zimmerman, R.D. and Johnson, E.C. (2005). Consequences of Individuals Fit at Work: A MetaAnalysis of Person-Job, Person-Organization, Person-Group, and Person-Supervisor Fit. Journal of Personnel Psychology, 58(2), 281-342. Crossref

- Kular, S., Gatenby, M., Rees, C., Soane, E., Truss, K. (2008). Employee engagement: A literature review. Working Paper. Kingston University.

- Markos, M, \& Sridevi, M. (2010). Employee engagement: The key to improving performance. International Journal of Business and Management. 5(12), 89-96.

- May, D. R., Gilson, R.L., \& Harter, L.M. (2004), The psychological conditions of meaningfulness, safety and availability and the engagement of the human spirit at work. Journal of Occupational \& Organizational Psychology. 77, 11-37. Crossref

- Meyer, J. \& Allen, N. (1997), Commitment in the Workplace: Theory, Research, and Application, Sage Publications, Thousand Oaks, CA. 
- Morrow, P.C., \& McElroy, J.C. (1987). Work commitment and job satisfaction over three career stages. Journal of Organizational Behavior, 30,330-346. Crossref

- Netemeyer, R.G, Boles, S. B., Mckee, D. O. (1997). An investigation into the antecedents of organizational citizenship behaviors in a personal selling context. Journal of Marketing, 61, 85-98. Crossref

- O'Reilly, C. A., Chatman, J. A., \& Caldwell, D.F. (1991). People and organizational culture: A profile comparison approach to assessing person-organization fit. Academy of Management Journal. 34(3), 487-516. Crossref

- Perrin, T. (2003). Working today: Understanding what drives employee engagement. Towers Perrin Talent Report U.S Report.

- Rich, B.L., Lepine, J.A., \& Crawford, E.R. (2010). Job engagement: Antecedents and effects on job performance. Academy of Management Journal, 53, 617-635. Crossref

- Robbins, S. P. (2006). Perilaku Organisasi. Edisi kesepuluh. PT Indeks Kelompok Gramedia, Jakarta.

- Rynes, S.L. \& Barber, A.E. (1990). Applicant attraction strategies: An organizational perspective. Academy of Management Review, 15, 286-310

- Salanova, M., Llorens, S., Cifre, E., Martínez, I. M. (2014). We need a hero! toward a validation of the healthy and resilient organization (HERO) Model. Group \& Organization Management, 37(6), 785-822. Crossref

- Schaufeli, W. B., \& Bakker, A. B. (2003). Utrecht Work Engagement Scale: Preliminary Manual. Department of Psychology, Utrecht University, The Netherlands (available from www.schaufeli.com)

- Schaufeli, W.B. (2012). Work engagement. What do we know and where do we go? Romanian Journal of Applied Psychology, 14(1), 3-10.

- Schaufeli., Salanova, M., Gonzalez, R.V. \& Bakker, A.B. (2002). The measurement of engagement and burnout: A two sample confirmatory factor analytic approach, Journal of Happiness Studies, 3, 71-92.

- Schneider, B., Goldstein, H.W., \&Smith, D.B. (1995) The ASA framework: An update. Personnel Psychology. 48, 747-779. Crossref

- Scroggins, W. A. (2008). Antecedents and outcomes of experienced meaningful work: A person-job fit perspective. Journal of Business Inquiry. 7, 68-78.

- Sekiguchi, T. (2004). Person-Organization Fit and Person-Job Fit in Employee Selection: A Review of the Literature. Osaka Keidai Ronshu., 54(6), 179-196.

- Silverthorne, S. (2004). The impact of organizational culture and person-organization fit on organizational commitment and job satisfaction in Taiwan, Leadership \& Organization Development Journal, 25(7), 592 - 599.

- Super, E.D. (1957). Career Development: Self Concept Theory. College Entrance Examination Board. New York.

- Torrente, P., Salanova, M., Llorens, S., \& Schaufeli, W.B. (2012). Teams make it work: How team work engagement mediates between social resources and performance in teams. Psicothema, 24, 106-112. 